\title{
ANCESTOR WORSHIP \& DISRUPTED CONTINUITY AMONG \\ INTERNALLY DISPLACED PERSONS (IDPS) IN GEORGIA
}

\section{// NANA CHABUKIANI}

ABSTRACT // Due to the Russian-Georgian military conflict in 2008, thousands of ethnic Georgians had to flee from their villages in South Ossetia and move to new settlements built for what were now termed internally displaced persons (IDPs). Through displacement, IDPs lost their connection with their places of origin and, consequently, their connection with their ancestry. Based on ethnographic research conducted in the Koda IDP settlement, the article explores how rituals related to the deceased help IDPs sustain belonging to their family lineage. The article illustrates that verbal commemoration, and in particular toasting, gives IDPs an opportunity to maintain presence of the deceased within their social group. While verbal commemoration is sufficient for this, tangible objects also seem to play a significant role. The place of burial and the soil provide an opportunity for the continuation of the social group of the extended family and its constant re-creation. 


\section{INTRODUCTION}

arejan's death came as no surprise to her relatives. She was 83 years old and had already been sick for months. She was an 'internally displaced person' (IDP) from South Ossetia and, according to her daughter-inlaw, her health suffered greatly after they left their home village. Darejan was buried in accordance with burial customs common for people from South Ossetia. First, the panashvidi ${ }^{1}$ was organised. The coffin was placed in the middle of the living room, and the chairs arranged along the walls, around the coffin. Family members and close relatives sat on these chairs while newcomers walked around the room, met all the family members and offered condolences. Champagne, water and fruits were on display in the room for the deceased. A candle was lit for her soul. After three days, Darejan was buried. Cars and minibuses took everybody to the cemetery. There, the coffin was placed in the ground. Family members drank wine and toasted to their beloved departed. Finally, Darejan's son brought forth a small fabric bag and spread soil all over the grave. This was soil from South Ossetia, the place where Darejan 'belonged' and the place which she had needed to leave due to the military conflict in the region.

This article tells the story of IDPs from South Ossetia and illustrates how deceased ancestors help the living to keep their sense of belonging to the community - that is, to their family lineage - after being forced to flee their home villages. The article explores the importance of relatives' graves for preserving the IDPs' memory, traditions, and a sense of belonging to their ancestors. It is based on ethnographic research done in the Koda IDP settlement in April-May 2013, which comprised participant observation together with 12 in-depth interviews with IDPs, and illustrates that one of the main ways to keep social belonging to the community is through rituals concerned with death and the deceased such as toasting and visits to the grave. Toasting to the dead plays a significant role in retaining the deceased as a part of social life, while tangibles such as graves are significant since the process of re-creating the ancestral community is believed to be possible only through the soil.

\section{THE AUGUST 2008 WAR AND THE KODA IDP SETTLEMENT}

On 8th August 2008, with the first military attack on villages in South Ossetia, the so called five-day GeorgianRussian war began. The conflict concerning the region of South Ossetia (in this article also referred as the Tskhinvali region) first started in the 1990s. South Ossetia is located in the northern part of Georgia and shares a border with the Russian Federation. The first major conflict happened in 1991-1992 which resulted in 251,000 local ethnic Georgians fleeing from the Abkhazia and Tskhinvali regions (Gamisonia and Pertaia 2009). Tensions arose for a second time in 2004, reaching a peak in 2008 when war broke out and an additional 26,000 people had to leave their homes and received the status of IDPs (Gamisonia and Pertaia 2009).

Internally displaced persons (IDPs) have a special legal status in Georgia. According to Georgian law, IDPs are people who must leave their homes due to a threat to their lives or the lives of their family members. In order to receive recognition of their status, IDPs have to register at the Ministry of Refugees and Accommodation (MRA) of Georgia, which then decides whether or not to provide the person with the official status of an IDP. After receiving official recognition of their IDP status, people gain certain benefits: for example, they receive monthly financial support from the Georgian government, they are exempted from utility payments, and are allotted a flat in an IDP settlement.

Such settlements were built by the Georgian government in various regions of Georgia in order to solve the housing problem of the IDPs. According to Transparency International Georgia (2010), 13 settlements were built between October and December 2008. IDPs that previously had to find shelter with their relatives either in Tbilisi (the capital city) or in Gori (the nearest large city to the Tskhinvali region) could now move to flats in these new settlements. One of the IDP settlements was built in the village of Koda, located in the Tetritskharo district in the KvemoKartli region, a 40-minute drive from Tbilisi. According to the Georgian MRA, nowadays there are around 1,600 IDPs in Koda (Ministry of Refugees and Accommodation n.d.). The place where IDPs now reside used to be a military settlement under the Soviet Union. After the August 2008 conflict, the ruined buildings were renovated so that IDPs could use them as flats. There are ten five-storey buildings with three flats on each floor. The flats vary in size (the smallest with only one and the largest with three bedrooms) and were distributed according to the number of family members. The IDPs were provided with a small fridge, a cupboard, a kitchen table and chairs, beds, a wardrobe and a TV set.

\section{ANCESTOR WORSHIP IN GEORGIAN CULTURE}

IDPs lead a tough life in the settlement. Unemployment, financial problems and an environment which radically differs from what they are used to are difficulties that they have to face daily. Not being able to practice traditional rituals creates additional dissatisfaction. Burial rituals are especially crucial for IDPs, as their sense of belonging to the family - which consists not only of living members, but also of the deceased - is defined by performing them. Not being able to perform the rituals thus threatens family identity.

\footnotetext{
${ }^{1}$ A period of several days before the funeral when relatives and friends can visit the family of the deceased and offer condolences.
} 


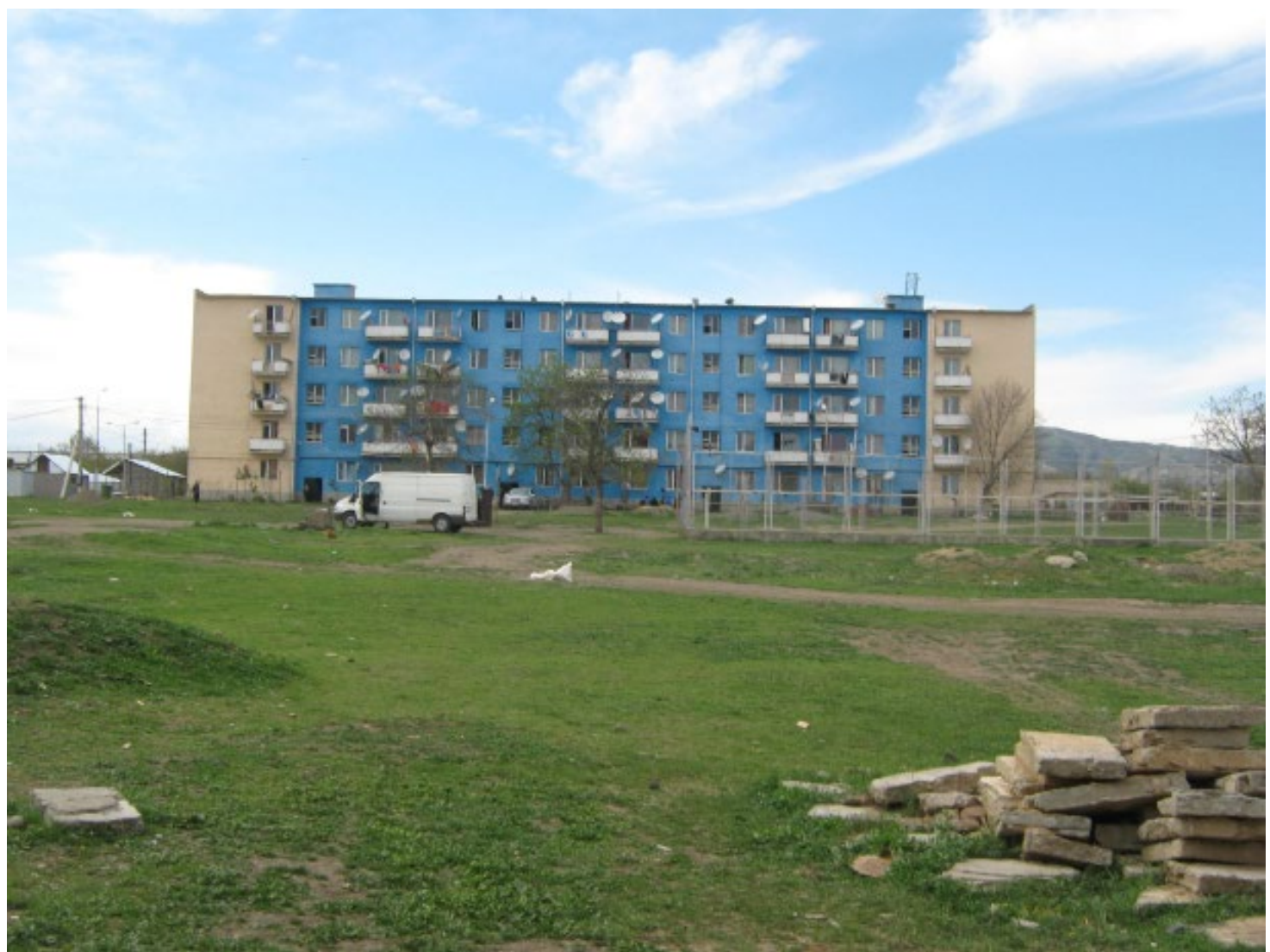

A building in Koda IDP settlement

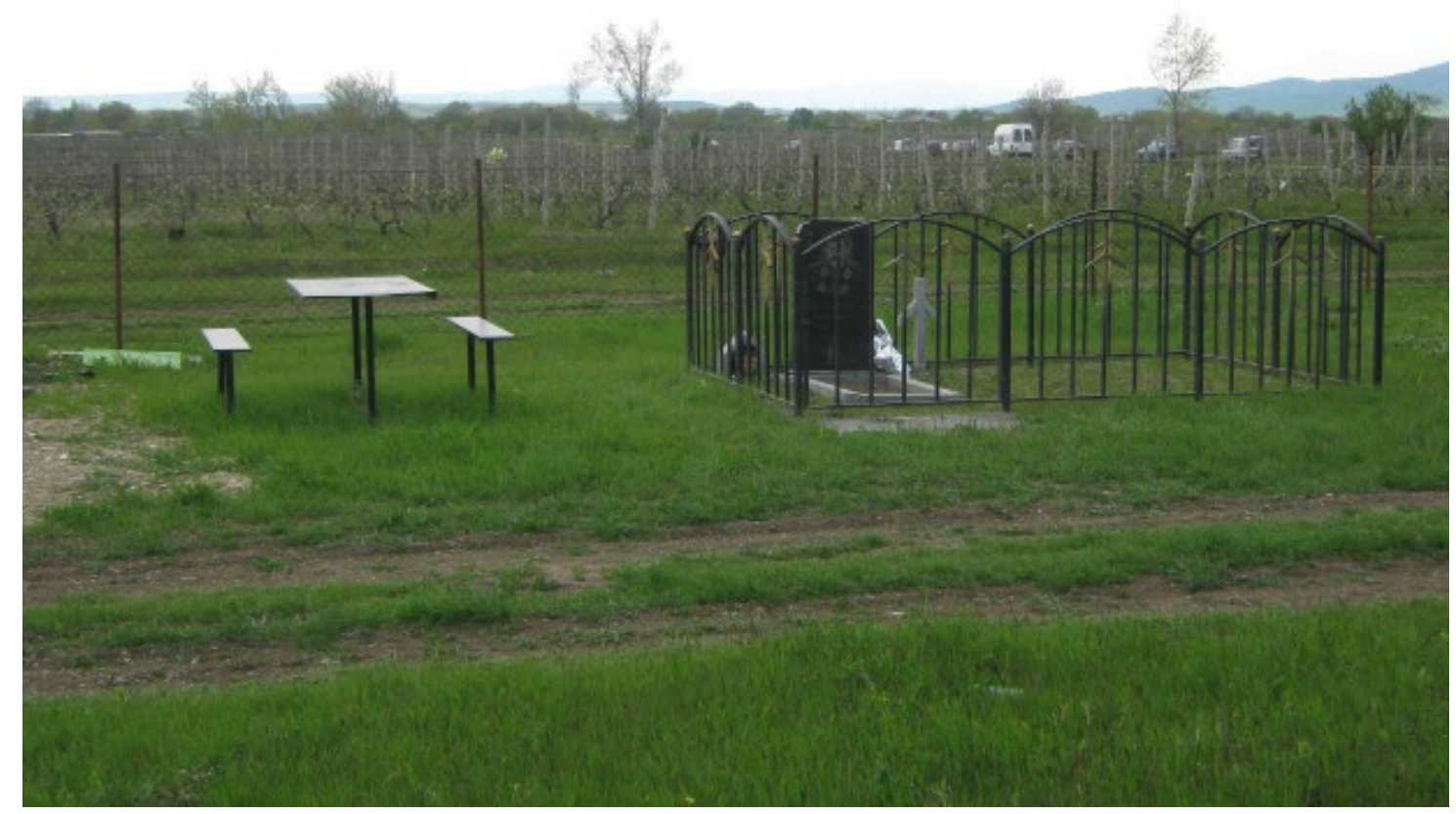

A bench and a table next to a grave 
Ancestor worship is a common practice in various cultures. For example, Bloch and Astuti (n. d.) write about the existing communication with the ancestors in Vezo, Madagascar. They claim that even though the people are aware that the ancestors are dead, they remain present in the social world of those who are alive and continue to play an important role in the lives of the living by contributing to their sense of identity. As for Georgian culture, Khutsishvili (2009) discusses the importance of the deceased among the living and argues that not only are the deceased a part of Georgian society, but people also keep communication with them through their dreams.

Rituals related to ancestors are firmly connected with material representations of the deceased. Radley (1990) underscores the importance of material objects in the process of remembering. He claims that memory cannot be limited only to its psychological understanding, as remembering is not only something individually specific stored in a person's brain, but also takes place as a social process with material and oral components. Intentionally or unintentionally, people create material objects which live longer than the creators and ensure people's existence after their biological death. Hallam and Hockey (2001) argue that material objects such as photos or graves keep the memory of the deceased alive through practices related to them. According to these authors, various death rituals involve material objects, visual images and written texts which mediate relations with the deceased (Hallam and Hockey 2001: 2). Hallam and Hockey claim that after death, people disappear from the view of those still living, creating a possibility that they might be forgotten (2001:5). As a reaction to this, the living try to create a symbolic representation of dead relatives as an attempt to keep them 'alive'. As the authors put it, 'where material objects are designed as aspects or extensions of persons, they can become potent resources of memories' (Hallam and Hockey 2001:14). Thus, dead people continue to be a part of this world through material objects as they evoke memories.

Material objects indeed played an important role in sustaining the memory of the deceased for IDPs from the Koda settlement. Various belongings of the deceased clothes, photos, letters, even a dagger - were kept by my correspondents. But the most important material representation of the deceased is their grave. Graves of ancestors have to be treated with respect, visited frequently, and cleaned. Custom requires visiting a grave several times throughout the year. When a person dies, their grave has to be visited on the second day after burial, on the ninth and fortieth days, and one year after death. This timeline is connected to Orthodox Christian doctrine according to which the soul requires 40 days until the Lord judges them and decides whether they should go to heaven or to hell. During these 40 days, the soul approaches God, and on the second and ninth days, it encounters the most difficult crucibles, thus needing special care and prayers from the living. ${ }^{2}$ Furthermore, one's grave is visited a year after their death. It is believed that the mourning pe- riod should last for one year and the end of mourning is celebrated (Chikovani 1987). After a year has passed since their death, individuals join the other deceased and are visited on various religious celebrations such as Easter, St. Mary's Day and the Ascension of Christ. Whenever one visits the graves, they have to bring food for the dead, make a small supra ${ }^{3}$ and say shendoba. ${ }^{4}$

Graves are not the only sites where Georgians can commemorate their deceased, but also places that create a social space for communication with the dead and become a place where a continued connection with the deceased is possible. Graves are considered to be houses for the deceased (Williams 2003). Thus, visiting the grave means visiting a deceased relative. Manana (female, 56) told me in an interview: "When I used to go there, I had a feeling that I would enter his world, his house... [The deceased] need to have a place somewhere, so that we can visit them. Otherwise, they will be lost."

The grave itself is also constructed in a way that the deceased can easily 'receive guests.' Usually, a table and a bench are constructed near the grave for visitors to sit down and have some food and drink. Nona (female, 40) described how they constructed graves in their previous villages:

We used to make an iron fence around the grave, so that dogs or other animals could not go inside and spoil it. We would cover the ground across the fence with red soil... beautifully... And we would put a table and benches, so that on holidays, when we would visit graves we could sit there comfortably.

Though Nona acknowledges that the deceased are gone, she also holds that visiting the grave is worthwhile due to feeling closer to the deceased.

\section{TOASTS AS A SUBSTITUTE FOR GRAVES}

After their displacement, IDPs no longer have direct access to the graves of their ancestors, and did not manage to bring with them any material representation of their deceased relatives. They thus cannot perform the rituals in the same way as they did in their home villages. It is obvious that visiting the graves creates a sense of belonging to the family heritage, which is defined by the line of ancestors. It creates a sense of having a certain past, and provides an opportunity for the living to build a future upon it. Losing access to graves was a great loss for IDPs.

\footnotetext{
${ }^{2}$ As told to the author by a priest from Tbilisi (interview, 25 April, 2013).

${ }^{3}$ A table with food and wine and/or a dinner which includes not only family members but guests as well.

${ }^{4}$ Commemoration and blessing of the deceased by saying a toast.
} 
As the interviews showed, one of the main reasons for IDPs to return back to their villages is visiting the graves of their ancestors.

However, the IDPs did not lose their connection with the deceased and still maintained them as part of their social world. This became possible through dinners and toasting. Every time friends or relatives get together for dinner, they commemorate their deceased. As Manana (female, 56) said, 'We talk about them whenever we have guests. We say toasts for them'. The second toast during the supra is always dedicated to dead relatives.

Supras and toasting are important parts of Georgian culture. As the Georgian ethnographer Gotsiridze (2007) puts it, the phenomenon of the Georgian supra contains elements of people's religious and social world views. According to him, dinner had a sacred meaning for Georgians, which is still true to some extent: having dinners together is the most frequent way of socialising between people, and by toasting for the dead during such events, the deceased are not only commemorated but also become part of a social interaction between themselves and those who are still alive.

\section{IMPORTANCE OF PLACE AND SOIL}

However, according to the respondents graves cannot be substituted so easily. It is believed that the soul of a person stays at the place where they are buried: a soul is attached to the grave. On the one hand, IDPs believe that the soul remains on earth after a person's death for 40 days, but ascend to heaven afterward, as taught by the Orthodox Church. However, various examples illustrate that souls are believed to stay attached to the place where they 'belonged.' This belonging can be created both through living at a certain place and/or being buried there. Abesalom's (male, 65) example shows that the concept of the soul is not that simple. Abesalom was worried about the fact that his father was buried in their village, while his mother was buried in Koda: 'They say people meet each other after death... Now [as they are buried apart] how will they meet each other?' Similarly, Manana (female 59) said that people should not visit the graves of the relatives on Easter as the deceased leave graves for a while also to celebrate Easter somewhere else. Thus, for these respondents, the soul remains attached to the place where a person is buried and continues to exist as they used to in 'this world.'

A place of burial is essential and people should be buried in their villages. Manana (female, 56) said that a person should be buried in the village where they were born: 'It is desirable to bury a person at her own place, her village, her land or soil... Whenever I see my husband in my dreams, I always see him in his village...' For Manana, as for all my respondents, dreams are an important source of information, and, for her, these dreams mean that her husband's soul remains close to his village.
The respondents relate the importance of place to Christian belief. They argue that according to Christianity, humans were created from the soil: 'God created Adam and Eve from soil' (Gela, male, 60). Moreover, the soil is the substance into which humans will transform in the future. It is their future condition - through burial and graves people re-unite with soil. 'We will also end up in graves, right?' (Manana, female, 56). The particular soil in their village is what they were created from as well as what they are going to be in the future. This attitude creates a special attachment to the place where people were born:

The processes of transformation are going on inside the land. This is why one must not lose any territory. Your neighbor's territory is your neighbor's territory, and yours is yours. The future has to continue, right? (Gela, male, 60)

Through the soil, IDPs keep a connection with the past and preserve continuity with the present. Descendants come from the soil, while ancestors are transformed into soil after death. A person, his ancestors, and his descendants seem to be parts of the same constantly renewed entity.

The above mentioned understanding of soil creates a special attitude to place. Various authors (David and Willson 2002; Hornstein 2011) argue that place gains meaning through the material culture, architecture, or other objects created by people. However, the case of IDPs from South Ossetia shows that place/soil is important as it itself becomes a material representation of the dead and is a source of unity between the dead and the living.

The unity and continuity with the deceased which was created through place and soil cannot be maintained after resettlement. The souls of the deceased were left behind in previous places whereas the living needed to re-locate elsewhere. Verbal commemoration through toasting keeps the deceased in the social life of the living, but the cyclical reunion of the community is lost. By displacement, the 'unity' has collapsed and IDPs have lost their ties with their ancestors.

IDPs were provided with new cemeteries at their new places of residence. However, Koda is not considered the proper place to bury a person. At Darejan's funeral, the relatives were very sad that they had to bury her at a place where she did not belong - meaning that she was not born there, her ancestors did not live there, and she did not spend her life there. Quite often one could hear the Georgian saying sadauri sada kvdeba-quoted to the effect that a person from other part of the country died there, and regretting the fact that the deceased had to be buried in a place to which they did not belong.

Thus, IDPs use alternative ways to bring their deceased closer to the places to which they belonged. Some try to bury their deceased in Gori, which is closer to the Tskhinvali region. Others manage to procure soil from 
South Ossetia and scatter it over the graves, as described in Darejan's case in the introduction. However, the new place is still not 'their place.' The special attitude to the soil and place disrupts IDPs and prevents them from fully adapting to their new place of residence.

\section{CONCLUSION}

Ancestors play a crucial role in Georgian culture, as they are directly a part of the social life of living Georgians. Graves are places where the commemoration of the deceased as well as interaction with them becomes possible. The South Ossetian IDPs in this ethnographic study have had to leave the graves of their ancestors behind and have no access to them after the military conflict in the region. Lack of access to the graves and no possibility to perform the rituals threatens continuity of the family lineage and the social reproduction of society. The living manage to keep the deceased as a part of their community through toasting during dinners. However, graves are significant as more than just a place where commemoration is possible. Graves are a means of being reunited with the soil. Soil is crucial as it is a source of the future - people are created from soil - and it also represents the past - ancestors turn into soil after their burial. Through burial at the place where people lived, the continuity of the community can be sustained; but this continuity is disrupted by displacement, making it more difficult for the IDPs to adjust to the new place of their residence.

\section{ACKNOWLEDGEMENTS}

I would like to use this opportunity to express my gratitude to my supervisor, professor Vlad Naumescu, whose advice and suggestions have been a great support throughout the research process. I also would like to thank the reviewers of "The Unfamiliar" whose comments were helpful not only to improve this particular paper but also to work on the topic in the future. And finally, I am grateful to the staff members of the Koda Community Education center and my informants, especially Madona and Jemo, who assisted me during ethnographic field research in the Koda IDP settlement.

All photographs by the author. 
Bloch, M. and Astuti, R. (n.d) 'Are the Ancestors Dead?' (Unpublished manuscript).

Chikovani,T.(1987)8

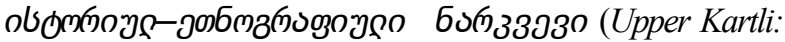
Historic-Ethnographic review). Tbilisi: Soviet Georgia.

David, B. and Wilson M. (2002) Inscribed Landscapes: Marking and Making Place. Honolulu: University of Hawaii Press.

Gamisonia, N. and Pertaia D. (2009) গy

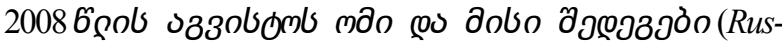
sia-Georgia Conflict and its Consequences). Tbilisi: Universali.

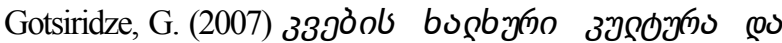

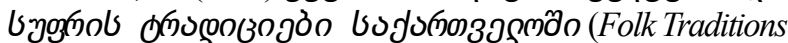
of Eating and Dinners in Georgia). Tbilisi: Tbilisi State University Press.

Hallam, E. and Hockey J. (2001) Death, Memory and Material Culture. Oxford and New York: Berg.

Hornstein, S. (2011) Losing Site: Architecture, Memory and Place. Surrey and Burlington: Ashgate Publishing Company.

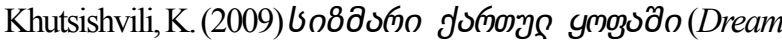
in the Traditional Georgian Being). Tbilisi: Universali.

Ministry of Refugees and Accomodation (MRA). (n.d) 'IDP Issues. General Information' [online]. Available at: http://mra.gov.ge/main/ENG\#section/33 (last accessed 13 November 2013).

Ministry of Refugees and Accomodation (MRA). (n.d.) 'Figures on Internally Displaced Persons in Georgia According to Regions' [online]. Available at: http://mra. gov.ge/main/ENG\#section/50 (last accessed 13 November 2013).

Radley, A. (1990) 'Artefacts, Memory and a Sense of the Past'. Pp. 46-59 in Middelton, D. and Edwards, D. (ed). Collective Remembering. London, Newbury, and New Delhi: Sage Publications.

Transparency International Georgia. (2010). Cottage Settlements for Georgia's new IDPs: Accountability in Aid and Construction [online]. Available at: http:// transparency.ge/sites/default/files/post attachments/ Report IDP_Cottage_Settlements 27_April_2010.pdf (last accessed 13 November 2013).

Williams, P. (2003) Gypsy World: The Silence of the Living and the Voices of the Dead. Chicago and London: University of Chicago Press. 
